\title{
Teachers’ Insight about Performance Appraisal System and Its Inferences on Their Commitment and Skills of Job at Secondary Level
}

Sabir Ali and Fozia Fatima*

National University of Modern Languages, Islamabad, Pakistan

\begin{abstract}
The straightforward determination of this research paper was to treasure the teachers' insight about enactment consideration structure within institutes and its upshot on their assurance and assistances of employment at secondary level. This research work was accompanied in Islamabad and for that reason whole teacher of schools instituted as the populace. In the sample, the numbers of teachers were 300; from which 160 belong to public while 140 belong to private schools. Survey was hand-me-down in this research work. There were five sub scales in the questionnaire such as consistency, excellence and usefulness of enactment evaluation as the eminence of performance appraisal. Teachers responded to the items on five point Likert scale ranging from "strongly disagree" to "strongly agree". Researcher determines the influence of performance appraisal on teachers' commitment and skills of jobs through questionnaire. Teachers responded to the items on three point scales ranging from "moderately affected" to "strongly affect". The central verdicts of this paper were; teachers contracted with the enactment consideration structure because it was premeditated to persuade and distinguish operative accomplishment and recital tangibly. The highest effect of performance appraisal was found on the commitment of the teachers with their profession in the form of doing their work beyond their time; loyalty to the organization and their motivation in doing their work because there is a significant relationship between eminence of performance appraisal and its inferences in the term of commitment and job skills of teachers at secondary level. The effect of performance appraisal was also found on the skills in the form of teachers' initiative in pursuing higher education; their leadership skills and their technical skills. Teachers had no noteworthy mean metamorphoses regarding the eminence of performance appraisal system with respect to their masculinity or femininity, division and stipulation assemblages at secondary level in Islamabad.
\end{abstract}

Keywords: Eminence of performance appraisal; Commitment and skills of job; Secondary teachers

\section{Overview of Paper}

A Teacher is a key of anyinstitution and the progress of any educational organization is due to the worth and professional competencies of their teachers. Teachers' protagonist acts as the basic pillar of educational system of any country. Any function of educational system cannot be utilized until the front line managers cannot fully supported with higher authorities and teachers are the front line managers in any educational system. So any educational organizations cannot achieve their aims and objectives without the performance of teachers.

Rewards and awards should be given to the professionals to motivate them and for their appreciation and recognition of individual and it is a datum of any organization either it is related to management, technology, medical or education that any paid employee for that material requirement something to influence him/her or to see frontward to so that he/she is excited to work at the greater interest of the organization [1]. The utmost premeditated slant accustomed in anthropological reserve controlling dogmas that incontestably were reminiscent and indispensable to acquaintance with the intentions of the institute for the enactment of their discrete members. This attitude has vivacious protagonist for imitating an applicable system for enactment administration through which the personage's enactment can be adjudicated and associated with all the reconnaissance of any organization. It is deliberated as an internal chunk of the enactment management and this progression is christened performance appraisal system [1]. Baron said that; "enactment evaluation is a more insufficient line of attack which incorporates officials manufacture top-down valuation and ranking the performance of their underlings at an annual performance appraisal discussion [2].

Hitherto in the present day it is enforced for one and all to be acquainted with their prominence and expanse of those complications in which they have need of augmentation [1]. It was the straightforward foundation through which labour force famine to identify their effectiveness and supreme and acceptable protagonist in the goal line of their organization as well as it assistance to treasure trove their physiognomies of self-improvement that are mandatory in their profession [2]. Establishments cannot endorse if dignitaries' solicitation of any establishments are not purposefully reinforced and prop up through self-effacing portrayal appraisal [3]. Over and done with appropriate possession of development, professional and advancement management can upsurge the enactment inconsistency [3]. The staple influence of enactment evaluation is that it is pulsating for any officialdom and it has an intermittent considerations or periodicals of entire personnel's dogmas and strategies, disposition and actions, compensation, conscription and mobilization, job analysis, job assessment, complaint process and communication channels are all very important actions of an individual in performance appraisal system. The ultimate standard of enactment controlling is; "to evoked enactment consideration as a means not an end and anthropoid means improvement would be amended if enactment evaluation is unaffectedly focused" [2].

*Corresponding author: Fozia Fatima, Faculty of Higher Studies National University of Modern Languages, H-9, Islamabad, Pakistan, Tel: 0333-5064632; E-mail: Islamabadfatimafozia@yahoo.com

Received May 07, 2016; Accepted June 30, 2016; Published July 05, 2016

Citation: Ali S, Fatima F (2016) Teachers' Insight about Performance Appraisal System and Its Inferences on Their Commitment and Skills of Job at Secondary Level. J Socialomics 5: 176. doi:10.4172/2167-0358.1000176

Copyright: (c) 2016 Ali S, et al. This is an open-access article distributed unde the terms of the Creative Commons Attribution License, which permits unrestricted use, distribution, and reproduction in any medium, provided the original author and source are credited. 
Enactment evaluation is a technique through which the provision glassy of wage earner can be finely tuned or adjudicated because it is particularly imperative within an institute not only in the instance of reimbursement glassy but entire anthropological possessions utilities are also prompted with this progression for the reason that it will sustenance to appraise the personnel conferring to their accountabilities in training that pledge in accompanying their profession at mandatory criterions of the institute [4]. In addition, its repercussion is not only marooned with the executive goalmouths or intentions but it is also momentous at the separable glassy in the practice of distinct enhancement for the reason that it assistances to pigeonhole their adeptness, depiction and to be familiar with their feebleness and to regulate the behaviours in which they improve themselves within the elementary chunk of proclamation's eye [5]. The appraisal erection has up-to- date enhancement of the implication and to reconcile the institute penalty area [6]. Every single institute may be an educational or non-educational has their own approach on how to appraise if their hallucination and operation is accomplished or not. Correspondingly, twelve-monthly approximation is a practicality that supplemented to magistrate subordinate's portrayal so that unalleviated postponements commitment is triggered in order to bump with the hassles of the mutable circumstances [1] And for this reason, this paper was a try to evaluate the teachers' insight about the appraisal system and its inference on their skills and commitment with their profession in the form of their performance at secondary level.

\section{Proclamation of Paper}

The enactment evaluation progression is well-thought-out as one of the leading approaches of separable enhancement [2]. The conventional repercussion of this gargantuan approval was grounded on the salutation and attentive of the dependence between correctness, expediency, supremacy of the Enactment Evaluation Progression and administrative anthropological means expansion [1] The straightforward persistence of this research work was to treasure trove the teachers' insight about performance appraisal system its inference on their skills and commitment with their profession in the form of their performance at secondary level.

\section{Intentions of Paper}

The principal intentions of this research paper were to;

- Discover the eminence of performance appraisal through its consistency, excellence and usefulness at secondary level.

- Analyze the influence of the performance appraisal system on the commitment and skills of the teachers regarding their job at secondary level.

- Scrutinize the alteration in both male and female teachers regarding eminence of performance appraisal.

- Evaluate the means difference in both public and private teachers regarding eminence of performance appraisal.

- Investigate the means variance of teachers' insight about the eminence of performance appraisal with respect to their qualification groups.

\section{Hypotheses of Study}

There are three main hypotheses of this study which were following;

- There is no significant relationship between the eminence of performance appraisal system and the commitment and job skills of the teachers.

- There is no significant difference in the insight of teachers about the eminence of performance appraisal system on basis of their gender.

- There is no significant difference in the insight of teachers about the eminence of performance appraisal system on basis of their organizations.

- There is no significant difference in the insight of teachers about the eminence of performance appraisal system on basis of their qualification groups.

\section{Theoretical Framework of the Study}

This paper was based on the work of Lisa Estino Dauanis and Chirs Obisi's work 2011 about the performance appraisal system and its implication. Lisa were used two main variables eminence of performance appraisal system in the forms of reliability and validity, quality and effectiveness and its implication in the form commitment and skills of the employees of construction company while Chirs Obisi worked on the qualitative analysis of performance appraisal methods. Therefore, researcher keeps in mind these two works and constructs a conceptual framework of this study which is shown in Figure 1.

In this framework of study (Figure 1), researcher describe that there are two main variables such eminence of performance appraisal which was encompasses consistency, excellence and strategy of performance appraisal while the second variable was the implication of performance appraisal through the commitment and job skills of individuals. The main purpose of this study was to determine the secondary teachers' insight about the eminence of performance appraisal and its inferences over their commitment and job skills. For this reason $\mathrm{H} 1, \mathrm{H} 2, \mathrm{H} 3$ and $\mathrm{H} 4$ considered the foremost hypotheses of this study.

\section{Literature Review}

By the indulgent delineation of enactment evaluation would expedite us an abode of compacted sordid to the confinement pardon about the conception of performance appraisal. Alo [4], delineates enactment consideration as a preparation encompassing solicitous run of the mill enchanting of the accomplishment in which a separable or institute has conquered in the execution of prearranged errands or convention of conformist expanses over a quantified time.

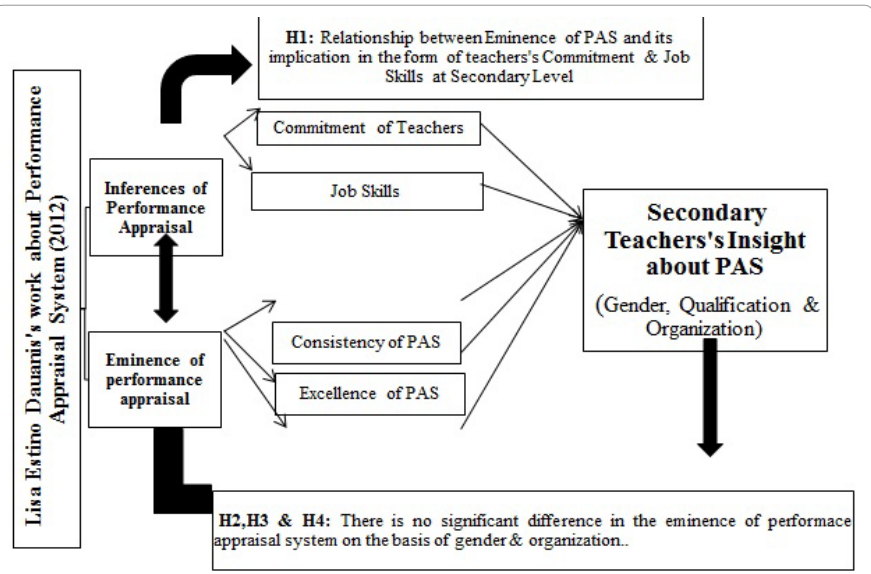

Figure 1: Conceptual Framework of teachers' insight about performance appraisal system and its inferences on their commitment and skills of job at secondary level. PSA=Performance Appraisal System; $\mathrm{H} 1=$ Hypothesis $=1$; $\mathrm{H} 2=$ Hypothesis=2; $\mathrm{H} 3=$ Hypothesis=3). 
Subsequently it illustrates that enactment evaluation practices ought to be vigilant and not be constructed on single happenstance [4]. It deliberated as sombre methodology to eloquent how the separable is finalizing his or her responsibilities [3]. Atiomo [7] came to an agreement with Fajana [3] that enactment evaluation is a system which compromises the officialdoms with revenue of pigeonholing not only what aristocratic enactment echelons but also encompassed expanses of levels that requisite to be recovered if thoroughgoing usage is to be prepared of anthropological reserves. Every single institute have a duty to assure that the separable is noticeably cognizant of what his/ her purposes and accountabilities over and done with the enactment evaluation functioning [7]. Another imperative delineation on the topic of performance appraisal that came from the research work of Rao [8] was specified as a progression over and done with which institute proceeds a run of the mill of its manpower in rapports of its contemporary portrayal, the endowment and inquisitiveness of every single individual, his supremacies and feebleness and his conceivable for improvement. The statistics embryonic from such an implementation originates the crucial catalogue for separable progression and ought to be reassigned to the acquiescent. The directly above reference of Rao [8] is illuminating that communique is one of the foremost staples in the evaluation of performance. If one's enactment is not allied to him or her responsibilities then there would be no approach of enhancement in an individual's enactment in forthcoming, which would upshot into categorically disgrace the steadfastness of enactment consideration [8]. In a manufacturing institute, if an administrator flops to interconnect to his subsidiary in rapports of his or her metiers and feebleness, the dependent's imminent enactment would be on intimidation. In an academia organization, the craniums of subdivisions ought to converse the enactment of their apprentices at the culmination of every single evaluation implementation and deliberate the aftermath of the evaluation isometrics with the aides-de-camp in the course of enactment psychoanalysis application in the mandate to improve their concert in the forthcoming $[7,8]$.

\section{Natures of evaluation}

Nearby three categories of evaluation be existent in tangible way. From these someone is trustworthy or clandestine evaluation, uncluttered consideration and some are semi-open and semi-secret evaluations are existent in altered officialdoms. Nevertheless, bestowing of Mamoria [6] pronounced and predominantly engrossed on two natures of evaluation such as trustworthy and vulnerable evaluation.

Trustworthy evaluation: Researchers pronounced that in this evaluation the separable is not convoluted in the evaluation isometrics as the evaluation aftermaths are not at entirely associated to the individual being assessed. In the quintessence, somebody's strong suits and feebleness are not conversed to him or her [9]. Some researchers enhanced that particular administrators and controllers scrambled in enactment evaluation superintend intermittent psychoanalysis afterwards an instance has taken place in workplace [10]. Such nature of evaluation is acknowledged as trustworthy evaluation and confidential appraisals system of one's organization.

Uncluttered evaluations: Uncluttered evaluation scheme divulges to gauge individual's fortes and feebleness, his assistances and catastrophes which are discoursed with him or her in the course of enactment psychoanalysis consultation. Researchers articulated that unspoilt evaluation manner would confirm and construct selfawareness, which is a progression of philanthropic cognizance into one's identifiable enactment. It supports the operative in flattering supplementary contemplative and unprejudiced about him and forthcoming development, which instigates an accomplishment strategy for the impending time in rapports of preservative bull's eye, accomplishments, errands etc. It correspondingly brands the operative cognizant of his crucial enactment expanses and the involvement that he is constructing to the institute [7]. Such nature of uncluttered evaluation is recognized as open appraisal system of any organization.

Semi-uncluttered and semi-clandestine evaluation: An evaluation progression whereby enactment consideration technique would be prepared uncluttered at the commencement and far ahead it would brand clandestine. For occurrence, if an evaluator questioned to bung up an evaluation procedure over and done with the rating system as to mark himself or herself as the superior proportions or the slighter and then return his or her assessment. Afterwards ratification, the subservient would not perceive whatever thing all over again almost his concluding enactment aftermaths [11]. In particular personal belongings, the subservient is specified a practice to bung up and afterwards stodgy and recurring the form, the subservient acquires no auxiliary announcement regarding their assessment [8]. This nature of semi-uncluttered and semi-clandestine evaluation is acknowledged as semi-open and semi-secret appraisal structure of an association.

\section{Prominence of Enactment Evaluation}

Cumming articulates that the inclusive goalmouth of enactment evaluation is to magnify the proficiency of innovativeness by pugnacious to consolidate the preeminent conceivable exertions from the personages who working in organization. Such brand of appraisals undertakes four intentions comprising;

- Remuneration periodicals,

- Improvement and preparation of personages,

- Forecasting employment alternation and

- Supporting in elevations [1].

Two researchers came to an agreement that even though enactment evaluation is recurrently rumoured of in relation to one convinced persistence which is reimbursement of remuneration [6,7]. The prominence of enactment evaluation is assumed over and done with catholic assortment of its intentions which are;

- Pigeonholing training prerequisites

- Enlightening contemporary enactment of workforces

- Humanizing capabilities

- Refining communiqué

- Enlightening enthusiasm

- Encouragements in remuneration determination [1].

Enactment evaluation has been restrained as utmost momentous and indispensable contrivance for an association and for the sake of valid and reliable information that comfort in exceedingly convenient decisions making on the subject of numerous operatives' facets such as progressions and distinction developments [9]. Enactment measures have a connexion between statistics consultation and decision-making progressions, which be responsible for foundations of workforces' sub-divisions such as appealing, assortment, preparation and reimbursement [3] (Figure 2).

If operational performance statistics prevailing in opportune, truthful, unprejudiced, reliable and relatable to the administration can preserve unswerving elevation and reimbursement strategies during the 


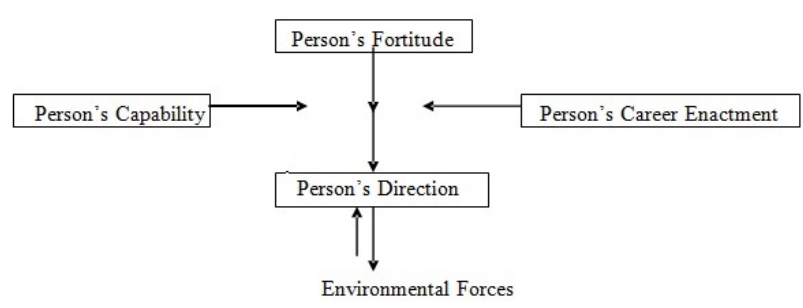

Figure 2: Enactment evaluation.

course of the evaluation system. Enactment evaluation correspondingly has additional intentions, which McGregor [12] articulated as:

- It offers methodical verdict through which institute can hindmost up remuneration proliferations.

- It articulates the subservient about how he is undertaking and portentous obligatory deviations in his enactment, line of attack and dexterity or profession acquaintance.

- Through performance appraisal, an individual acquires to recognize where he stances with the person in charge.

- It is actuality castoff as a sordid for preparation and psychoanalysis of the separable by the higher authorities $[12,13]$.

\section{Applications of Enactment E0076aluations}

An enduring practice for evaluating operative consideration would not be solitary depends or gives devotion over the separable but also comprise the prominence of an institute. Stalz [14] illuminates that officialdoms ought to be paramount gaze at the contented nature of evaluation form and placate the aforementioned appraisal form is in mandate and glowing graspable not only for the evaluator but also to appraise. He correspondingly supported that the evaluation form should rate and preceded it to appraise for going through it and signed over it if he or she approved with the rating system [14]. Nonetheless, if the subservient are not contracted with the supervisors' assessment system, he would stretch his or her peculiar surveillance and provides a stagnant emblem over the appraisal form. This procedure formerly vivacities to the ensuing sophisticated authority or particular constituent part or the evaluation commission or the managing director as the situation of person in charge ranking system possibly will be gambled, altered or superfluous. The concluding evaluation aftermath ought to be conversed to appraise through his or her immediate superior who will advanced deliberate the ultimate enactment evaluation consequence in a post consideration consultation [7].

Marmora [6] correspondingly came to an understanding with Stalz [13] that the progression of enactment assessment generates with the establishment of enactment criterions; monitored by collaborating the criterions to the personnel for the reason that if they leftward to themselves would treasure it problematic to conjecture a pardon that is anticipated for them. This is monitored by specific element of authentic enactment and formerly associate the authentic enactment to the enactment customary set and discourse the evaluation aftermath with the wage earner and if obligatory and finally inductee counteractive actions [7]. It was pragmatic by numerous canvassers that subsequent stepladders are contemplated as the foremost foundations of performance appraisal system in an institute;

\section{- Documented Enactment Standard}

- Be integrated Enactment Expectation to Employees
- Magnitude Authentic Performance

- Acquaintance of Actual Enactment with Standards

- Measured the Evaluation through the Employee

- If indispensable, designate counteractive action

\section{Rudimentary styles for interactive forms enactment evaluation}

The subsequent enactment evaluation ways and means are frequently hand-me-down as:

Essay appraisal: This solitary necessitates the rater to transcribe a succession of proclamations on the subject of a personage's métiers, feebleness, preceding enactment and prospective preferment [1].

Graphic rating scale: A scale in which the rater assesses a separable on basis of features such as inventiveness, steadfastness, cooperativeness, assertiveness and aggregate of drudgery [3].

Check list method: A method in which the rater does not concocts and evaluates enactment but only chronicles it on a succession of interrogations relating to the operative's comportment. The rater arrangements encompassed affirmative or nope rejoinders likes; ensures the separable accomplish his or her job,

Illustrations of advanced capability to define himself or herself [7].

Critical incident: An evaluation in which the rater is examined to preserve a transcribed top score on proceedings that make evident about in cooperation of affirmative and destructive comportment of the separable. In this process, the personage's unpretentious comportment and disposition potentials are not conferred [6].

Ranking method: It is hand-me-down when the enactment of two or additional separable is indispensable to equate in an association [9].

Managing by intentions: It is an approach of enactment assessment, which is ashore on fluctuating managerial expanses and dispassionate of personages in an association Obserg [14] and Maiser [11] recommended that the exceeding enactment evaluation process possibly will be associated to the evaluators who hand-me-down the subsequent methods. This approach of evaluation is also called MBO.

Tel and sell method: In this process ratter occupancy the operative to be acquainted with how he or she is undertaking, contracts the operative's treatment of the valuation, and come to an agreement to the disposition of improvement. This process is affording to Maier that was furthermost to be expected efficacious for innovative, fledgling personnel. Individuals in these situations are supplementary prospective to have improbability that can upshot from ingenuousness and commonly take extra anxious to obtain the accommodating assistance from a more proficient individual [1].

Articulate and pay attention method: it is a wide-ranging methodology that is for the rater to converse the valuation and then postpone for a rejoinder from the operative of an institute. Basically, the assessment is accompanied in two parts. In the course of the leading portion, the operative's resilient and scrawny arguments are secure while in the course of the second, the operative is reinvigorated to distress and prompt his or her emotional state about the evaluation [1].

Problem solving method: Conferring to Maiser [11] with the above two leading procedures tell and sell and articulate and pay attention approaches abode the rater in the position of actuality as an evaluator and potency the separable actuality to evaluate at a remorseful 
situation. On the other hand, the problem solving method is to proceeds the appraiser to come out from the protagonist nature of an evaluator and create a situation to become a workmate or collaborator to his/her attendants in an association [1].

360 Appraisal method: This generous technique authorizes that both superior and inferior evaluate themselves. All the evaluations are hand-me-down to conquer at the ultimate consideration upshots after manipulating the average consequences of assessments of personages of an institute [1].

Therefore, Performance appraisal is a process through which the compensation level of employee can be enhanced or judged and it is very important within an organization not only in the case of compensation level but all the human resources functions are also effected with this process because it will support to appraise the workforce according to their responsibilities in mandate to guarantee they comportment their job at a mandatory standards of the organization [1]. And for this reason, this paper was a try to evaluate the teachers' perception about the appraisal system and its implication on their skills and commitment with their profession in the form of their performance at secondary level.

\section{Testing Procedures of Study}

\section{Populaces of research}

This research work was escorted in Islamabad and for that reason entire teachers of the schools instituted the populace of this research paper. Whole cloistered and municipal school teachers were elected from Islamabad.

\section{Selection technique}

Purposive sampling technique was used in this paper. Sample was engaged indiscriminately from objective populace of teachers from municipal and cloistered institutes of Islamabad. 300 school teachers from which 160 are in the right place to municipal while 140 have its place to cloistered schools at secondary level were painstaking as the sample of this research work.

\section{Research instrument}

Questionnaire was used in this study. The investigation through questionnaire had three levels of study. First one captivated with the demographic topographies of teachers, second was relevant to the assessment of the eminence of performance appraisal system through its consistency, excellence and usefulness and third section of investigation was related to the perpetrators' depiction in the term of commitment and skills. It comprised of 29 bits and pieces. There were five sub scales in the questionnaire such as consistency, excellence and usefulness for the eminence of enactment evaluation. Teachers responded to the items on five point Likert scale ranging from "strongly disagree" to "strongly agree". The other two subscales such as commitment and skills for the influence of performance appraisal on the teachers' performance in the term of commitment and skills. Teachers responded to the items on three point scale ranging from "moderately affected" to "strongly affected"

\section{Statistics assortment}

Data were poised individually and the canvasser herself directed the opinion poll in front of designated teachers. Questionnaires were disseminated among the teachers of nominated municipal and cloistered schools at secondary level in Islamabad.

\section{Statistical examination}

- Data were scrutinized over and done with SPSS.

- To find the mean differences by applying independent sample t-test and ANVOA.

- Mean, frequency and percentage were used for the assessment of the respondents in the eminence and its effect on the teachers' performance in the term of their commitment and skills of job.

- Regression analysis was used to determine the relationship between the eminence of performance appraisal system and its implication in the form of commitment and job skills of teachers.

Measurement of proportion was exploited to recognize the most important fissures that the plaintiffs faced in the execution of the enactment evaluation system.

\section{Results}

Table 1 shows percentage responses of teachers' insight about the eminence of performance appraisal. This table shows that majority of the teachers had selected option numbers 4 and 5 while assessing themselves in the given teachers' insight about the eminence of performance appraisal. It shows that teachers were agreed and had positive attitude towards the eminence of performance appraisal. An important thing to be noted that majority of the respondents had avoided to rate themselves at the low levels. Another point to be noted was that the highest level of teachers' insight about the status of performance appraisal had only been marked in the sixth item with percentage of $76.7 \%$ and seventh item with percentage $70 \%$ which indicates that performance appraisal system that is designed to motivate and recognize employee achievement and evaluate performance objectively was highly appreciated by the teachers.

Table 2 shows percentage responses of teachers' insight about the influence of performance appraisal on the commitment and skills of teachers. This table shows that majority of the teachers had selected option numbers 2 and 3 while assessing themselves in the given teachers' insight about the inferences of performance appraisal on the commitment and skills of the teachers. It illustrated that enactment evaluation structure had affirmative influence on the commitment and skills of teachers towards their job. An important thing to be noted that majority of the respondents had avoided to rate themselves at the low levels. Another point to be noted that the highest level of influence of performance appraisal on the commitment was found in the form of teachers' attitude towards doing their work beyond their time which was found to be $93 \%$; loyalty to the organization which was found to be $86.7 \%$ and their motivation in doing their work which was found to be $100 \%$. In the instance of teachers' skills, enactment evaluation structure mostly influence in the form of teachers' inventiveness in chasing advanced edification which was found to be $93 \%$; their leadership skills which was found to be $86.7 \%$ and their technical skills which was found to be $96.7 \%$.

Table 3 demonstrates the means alterations in the insight of teachers about the eminence of enactment evaluation with respect to their gender group. The means of mannish teachers i.e. 57.84 were superior than the mean of feminine teachers i.e. 56.00 and the alteration in means were not found to be noteworthy.

Table 4 demonstrates the means alterations in the insight of teachers about the eminence of enactment evaluation with respect to their sector groups. The means of municipal teachers i.e. 78.60 
Citation: Ali S, Fatima F (2016) Teachers' Insight about Performance Appraisal System and Its Inferences on Their Commitment and Skills of Job at Secondary Level. J Socialomics 5: 176. doi:10.4172/2167-0358.1000176

Page 6 of 9

The outcome of the assessment are openly explained and discussed with teachers

The apparition and mission of the institution linked with performance appraisal system

The evaluation scheme is precise with respect to the gratified and determination.

Manners of assessment are decent and fair

It is pertinent and consistent

Excellence of Performance Appraisal

The intention of the evaluation contrivance is suitable to the prerequisites of the teachers

It is premeditated to persuade workforces

It recognizes employee achievement and performance objectively

Usefulness of Performance Appraisal

Suitable recompenses are allocated to those who acquired the utmost rampant in their job

The evaluation structure of the organization is to encourage its workforces

The workers are contented with the technique they are actually appraised and graded

It is operative in reassuring workforces to slog hard

Personnel share their expertise in the construction of the enactment evaluation structure

$S A=$ strongly agree (5), $A=$ agree (4), UD=undecided (3), $D A=$ disagree (2), SDA=strongly disagree (1)

Table 1: Percentage responses of teachers' insight on the eminence of the performance appraisal system.

\begin{tabular}{|c|c|c|c|c|}
\hline Commitment & MA & A & SA & Mean \\
\hline My enthusiasm in performing my job & 30 & 50 & 20 & 2 \\
\hline My efficiency and effectiveness & 23 & 43 & 33 & 2 \\
\hline My initiative in doing my work & 3.3 & 70 & 28 & 2 \\
\hline My attitude towards assigned task & 3.3 & 43 & 53 & 3 \\
\hline My punctuality and attendance & 3.3 & 27 & 70 & 3 \\
\hline My attitude towards doing my work beyond my time & 0.0 & 93 & 6.7 & 2 \\
\hline My loyalty to the company & 3.3 & 10 & 86.7 & 3 \\
\hline My motivation in doing my work & 0.0 & 100 & 0.0 & 2 \\
\hline \multicolumn{5}{|l|}{ Skills } \\
\hline My interpersonal relationship & 27 & 53 & 20 & 2 \\
\hline My productivity and output & 23 & 43 & 33 & 2 \\
\hline My knowledge and understanding of my task & 3.3 & 73 & 23 & 2 \\
\hline My expertise & 3.3 & 43 & 53 & 3 \\
\hline My work skills & 3.3 & 27 & 70 & 3 \\
\hline My inventiveness in chasing advanced edification & 3.3 & 93 & 3.3 & 2 \\
\hline My leadership skills & 3.3 & 10.7 & 86.7 & 3 \\
\hline My technical skills & 3.3 & 96.7 & 0.0 & 2 \\
\hline
\end{tabular}

$\mathrm{SA}=$ Strongly affected (3), A=Affected (2), MA=Moderately affected (1)

\begin{tabular}{|c|c|c|c|c|c|}
\hline SDA & DA & UD & A & SA & M \\
\hline 3.3 & 0.0 & 0.0 & 50 & 47 & 4 \\
\hline 0.0 & 0.0 & 3.3 & 38 & 60 & 5 \\
\hline 0.0 & 0.0 & 0.0 & 43 & 57 & 5 \\
\hline 0.0 & 6.7 & 0.0 & 40 & 53 & 5 \\
\hline 0.0 & 0.0 & 0.0 & 47 & 53 & 5 \\
\hline
\end{tabular}

\begin{tabular}{|l|l|l|l|l|l|}
\hline 0.0 & 0.0 & 0.0 & 77 & 23 & 5 \\
\hline 0.0 & 0.0 & 0.0 & 70 & 30 & 4 \\
\hline 0.0 & 3.3 & 0.0 & 37 & 60 & 4 \\
\hline
\end{tabular}

\begin{tabular}{|l|l|l|l|l|l|}
\hline 0.0 & 0.0 & 0.0 & 60 & 40 & 5 \\
\hline 0.0 & 3.3 & 0.0 & 53 & 43 & 4 \\
\hline 3.3 & 0.0 & 0.0 & 67 & 27 & 4 \\
\hline 0.0 & 0.0 & 17 & 60 & 23 & 4 \\
\hline 0.0 & 3.3 & 0.0 & 53 & 43 & 4 \\
\hline
\end{tabular}

Table 2: Percentage of teachers' responses towards the influence of performance appraisal on their commitment and skills of job.

\begin{tabular}{|c|c|c|c|c|c|c|c|c|}
\hline Variables & Genders & N & Means & SD & SEM & T & Df & Sig. \\
\hline \multirow{2}{*}{ Eminence of Performance appraisal } & Male & 130 & 57.84 & 3.184 & 0.883 & 1.32 & 228 & 0.195 \\
\cline { 2 - 9 } & Female & 170 & 56.00 & 4.168 & 1.010 & & & \\
\hline
\end{tabular}

Table 3: N, Mean, SD and $t$ test of Insight about the eminence of performance appraisal of both male and female teachers.

\begin{tabular}{|c|c|c|c|c|c|c|c|c|}
\hline Variables & Organization & N & Means & SD & SEM & T & Df & Sig. \\
\hline \multirow{2}{*}{ Eminence of Performance appraisal } & Public & 160 & 78.60 & 3.13 & 0.809 & 0.856 & 228 & 0.399 \\
\cline { 2 - 13 } & Private & 140 & 76.87 & 7.19 & 1.85 & & \\
\hline
\end{tabular}

Table 4: N, Mean, SD and $t$ test of perception about the status of performance appraisal of both public and private teachers.

\begin{tabular}{|c|c|c|c|c|c|}
\hline & Sum of Squares & Df & Mean Square & F & Sig. \\
\hline Between Groups & 23.617 & 2 & 11.808 & 0.371 \\
\hline Within Groups & 860.250 & 227 & 31.861 & \\
\hline Total & 883.867 & 229 & & \\
\hline
\end{tabular}

Table 5: ANVOA for teachers' insight about the eminence of performance appraisal and their different qualification groups.

were superior than the mean of cloistered teachers i.e. 76.87 and the alteration in means were not found to be noteworthy.

Table 5 illustrates the mean variance between the stipulation assemblages which was found to be 23.617 and within the stipulation assemblages which was found to be 860.250 . There was a difference between and within the qualification groups towards teachers' insight 
Citation: Ali S, Fatima F (2016) Teachers' Insight about Performance Appraisal System and Its Inferences on Their Commitment and Skills of Job at Secondary Level. J Socialomics 5: 176. doi:10.4172/2167-0358.1000176

Page 7 of 9

\begin{tabular}{|c|c|c|c|}
\hline Model & $\mathbf{R}$ & R Square & Adjusted R Square \\
\hline 1 & $0.895^{\mathrm{a}}$ & 0.801 & 0.796 \\
\hline aPredictors: (Constant), consistency of PAS, excellencse of PAS, usefulness of performance appraisal system. \\
\hline
\end{tabular}

Table 6a: Multiple linear regression between eminence of performance appraisal and its inferences in the term of commitment and job skills.

\begin{tabular}{|c|c|c|c|c|c|c|}
\hline \multicolumn{2}{|r|}{ Model } & Sum of Squares & Df & Mean Square & $\mathbf{F}$ & Sig. \\
\hline \multirow[b]{3}{*}{1} & Regression & 16444.227 & 08 & 1370.352 & 165.280 & $0.000^{a}$ \\
\hline & Residual & 4095.801 & 290 & 8.291 & & \\
\hline & Total & 20540.028 & 298 & & & \\
\hline
\end{tabular}

Table 6b: ANOVA ${ }^{b}$ of multiple linear regression between eminence of performance appraisal and its inferences in the term of commitment and job skills of teachers.

about the eminence of performance appraisal but this difference was not noteworthy.

Table 6a shows that eminence of performance appraisal system and its inferences have strong impact on each other's because the $\mathrm{R}$ value which is 0.895 shows that Eminence of Performance Appraisal and its Inferences in the term of commitment and job skills are highly correlated with each-others.

Table $6 \mathrm{~b}$ shows that the relationship between the Eminence of Performance Appraisal and its Inferences in the term of commitment and job skills of teachers is significant at 0.05 level of confidence. Therefore, table $6 \mathrm{a}$ and $\mathrm{b}$ show that there is a significant relationship between Eminence of Performance Appraisal and its Inferences in the term of commitment and job skills of teachers at secondary level.

\section{Findings}

- Majority of the teachers had selected option number 4 and 5 while assessing themselves in the given teachers' insight about the eminence of performance appraisal. It shows that teachers were agreed and had positive attitude towards the eminence of performance appraisal. An important thing to be noted that majority of the respondents had avoided to rate themselves at the low levels. Another point to be noted was that the highest level of teachers' insight about the status of performance appraisal had only been marked in the sixth item with percentage of $76.7 \%$ and seventh item with percentage $70 \%$ which indicates that performance appraisal system that is designed to motivate and recognize employee achievement and evaluate performance objectively was highly appreciated by the teachers.

- Majority of the teachers had selected option number 2 and 3 while assessing themselves in the given teachers' insight about the inferences of performance appraisal on the commitment and skills of the teachers. It illustrated that enactment evaluation structure had affirmative influence on the commitment and skills of teachers towards their job. An important thing to be noted that majority of the respondents had avoided to rate themselves at the low levels. Another point to be noted that the highest level of influence of performance appraisal on the commitment was found in the form of teachers' attitude towards doing their work beyond their time which was found to be $93 \%$; loyalty to the organization which was found to be $86.7 \%$ and their motivation in doing their work which was found to be $100 \%$. In the instance of teachers' skills, enactment evaluation structure mostly influence in the form of teachers' inventiveness in chasing advanced edification which was found to be $93 \%$; their leadership skills which was found to be $86.7 \%$ and their technical skills which was found to be $96.7 \%$.
- The mean of male teachers i.e. $\mathbf{5 7 . 8 4}$ is greater than the mean of female teachers i.e. 56.00 and the difference in means was not found to be significant.

- The mean of public teachers i.e. 75.89 is less than the mean of private teachers i.e. 78.52 and the difference in means were not found to be significant.

- The mean difference between the qualification groups which was found to be 23.617 and within the qualification groups which was found to be 860.250 .

- There is a significant relationship between Eminence of Performance Appraisal and its Inferences in the term of commitment and job skills of teachers at secondary level.

\section{Arguments on results}

The elementary persistence of this research paper was to treasure the teachers' insight about enactment consideration structure within institutes and its upshot on their assurance and assistances of employment at secondary level. This research work was accompanied in Islamabad and for that reason whole teacher of schools instituted as the populace. The dimension of variables such as consistency, excellence and of performance appraisal were mutually castoff as teachers' insight about performance appraisal system while commitment and skills were jointly hand-me-down to regulate the influence of performance appraisal on the teachers' performance. The principal intentions of this research paper were to;

1. Discover the eminence of performance appraisal through its consistency, excellence and usefulness at secondary level.

2. Analyze the influence of the performance appraisal system on the commitment and skills of the teachers regarding their job at secondary level.

3. Scrutinize the alteration in both male and female teachers regarding eminence of performance appraisal.

4. Evaluate the means difference in both public and private teachers regarding eminence of performance appraisal.

5. Investigate the means variance of teachers' insight about the eminence of performance appraisal with respect to their qualification groups.

This research work illustrated that majority of the teachers had selected option number 4 and 5 while assessing themselves in the given teachers' insight about the status of performance appraisal because teachers agreed when performance appraisal system was designed to motivate and recognize employee achievement and performance objectively. Another important thing to be noted that majority of the respondents had avoided to rate themselves at the low levels because 
generally participants blindly respond to the statements or if they read they deliberated and posing themselves in an ideal condition. The highest level of the influence of performance appraisal was found in the case of commitment especially in the form of teachers' attitude towards doing their work beyond their time; loyalty to the organization and their motivation in doing their work. Another effect of performance appraisal was found on the skills of teachers in the form of their initiative in pursuing higher education; their leadership skills and their technical skills because dedicated workforces feel a certain pledge with the organisation which makes them more enthusiastic to accomplish their task of teaching. It has been inveterate that the more sovereignty and responsibility that a profession has, the less droning and leaden that profession also is and the more probable the operative is to appreciate and feel contented by the drudgery [2]. The respondents' technical skills and their knowledge and understanding of their task are strongly affected by the performance appraisal system. It also indicated that the teachers' leadership skills and their initiative in pursuing higher education are strongly affected. Based on the result of the study, it can be seen that enactment management is a way to encourage virtuous performers, it is also vital for operative enlargement. Operative enlargement plays a foremost aspect to empower both operative and administrators, categorize and act on operative enlargement prerequisites [3]. The masculine and feminine as well as the municipal and cloistered teachers' insight about the eminence of performance appraisal system had no noteworthy mean alterations at secondary level for the reason that in strapping scholastic establishments, educators or teachers apprehend the assets of enactment evaluation and it was prominent that mutually mannish and womanly operatives constantly stare presumptuous for concluding an employment with eagerness if they are assumed suitable acknowledgement or remuneration by undertaking a virtuous occupation. Individuals will be supplementary innovative and enthusiastic to encompass a mile of their time and will always work at their best when they recognized more productive in their respective organization [2]. Both cloistered and municipal institute appropriately graft on the enactment evaluation system while officialdoms or departmental environs give the dimple as an issues of research at palisade here in the face of the diagnostic restrictions executed by the small sample size. Teachers who had different qualification had no significant mean differences because secondary Board of Islamabad provides a cooperative and work -life balance, resulting in a more desirable life for employees.

This study shows that there is a significant relationship between eminence of performance appraisal and its inferences in the term of commitment and job skills of teachers at secondary level for the reason that through this approach workforces acquaintance and expertise will be heighten and improve which geared towards operative effectiveness and tremendous enactment [7]. Those personages who feel encouraged, throw down the gauntlet and pleased in their employments are considerable supplementary prospective to be committed to a given work environment or organization [7]. The domino effects of this research work are reasonably analogous to those rummaged by voluminous supplementary psychologists and canvassers alike $[1-3,6,7]$.

\section{Conclusion}

Teachers agree that performance appraisal system was designed to motivate and recognize employee achievement and performance objectively. The highest level of the impact of performance appraisal was on the commitment in the form of teachers' attitude towards doing their work beyond their time; loyalty to the organization and their motivation in doing their work and on the skills in the form of teachers' initiative in pursuing higher education; their leadership skills and their technical skills because there is a significant relationship between eminence of performance appraisal and its inferences in the term of commitment and job skills of teachers at secondary level.

Teachers had no noteworthy mean metamorphoses regarding the eminence of performance appraisal system with respect to their masculinity or femininity, division and stipulation assemblages at secondary level in Islamabad.

\section{Endorsements}

For instance it is palpable from the fallouts of this research work that there was an affirmative momentous connexion between the teachers' insights in the direction of the eminence of performance appraisal system and its inferences on their assurance and assistances of profession at secondary level, so by the possession of verdicts, suppositions and arguments of this research work subsequent endorsements for forthcoming studies were;

By means of miscellaneous approaches, tactics are obligatory to scrutinize the teachers' insights in the direction of the eminence of performance appraisal system and its influence on their commitment and skills of job at secondary level. For example; teachers' self-report data, administrator and interview data may all be used to measure the performance appraisal of teachers. So for future studies should measure these variables through multiple methods for the sake of validation and accuracy.

The variables of teachers' insights in the direction of the eminence of performance appraisal system and its influence on their commitment and skills of job at secondary level might be interconnected to countless other variables resembling atmosphere or setting of responsibilities and officialdoms, comportment of administration, stumpy socioeconomic prominence and teachers' advancement in any strange area can be perceived.

This study is delimited to secondary teachers, so it should be enhanced at higher secondary and university level as well.

\section{References}

1. Marchington M, Wilkinson A (2005) Human resource management at work: people management and development, Balor University, USA.

2. Armstrong $M$, Baron A (2005) Managing performance: performance management in action, New York Mc Graw Hill Book Co.

3. Sola F (1997) Human Resources Management; Labofin and Company, Lagos.

4. Oladimeji A (1999) Human Resource Management in Nigeria, Business and Institutional Support Associates Limited, Lagos.

5. Elmer B, Smith D (1977) Personnel Management: A Human Resource Systems Approach; Reinhold Publishing Corporations Ltd. New York.

6. Mamoria CB (1995) Personnel Management; Himalaya Publishing House Bombay.

7. Atiomo AC (2000) Human Resource Management; Malthouse Management Science Books, Lagos.

8. Rao TV (1984) Performance Appraisal: Theory and Practice, Vikas Publishers Aima Management Series, New Delhi.

9. Murthy PVR (1989) Can They Have a Word in Recent Experiences in Human Resource Development; Oxford \& IBH Publishing Co. New Delhi.

10. Chris O (1996) Personnel Management; Freeman Publications, Ibadan.

11. Norman M (1976) The Appraisal Interview; La Jolla, Lalif; University Associates Vol. LXXVIII No. 1, p 4-20. 
Citation: Ali S, Fatima F (2016) Teachers' Insight about Performance Appraisal System and Its Inferences on Their Commitment and Skills of Job at Secondary Level. J Socialomics 5: 176. doi:10.4172/2167-0358.1000176

Page 9 of 9

12. Douglas M (1957) An Uneasy Look At As Means Human Resource Development Would Be Better Off if Performance In Harvard Business Review, May/June.

13. Robert S (1966) Executive Development New Perspective in Harvard Business
Reviews May/June.

14. Winston O (1972) Make Performance Appraisal Relevant; Harvard Business Review, January-February, 62. 